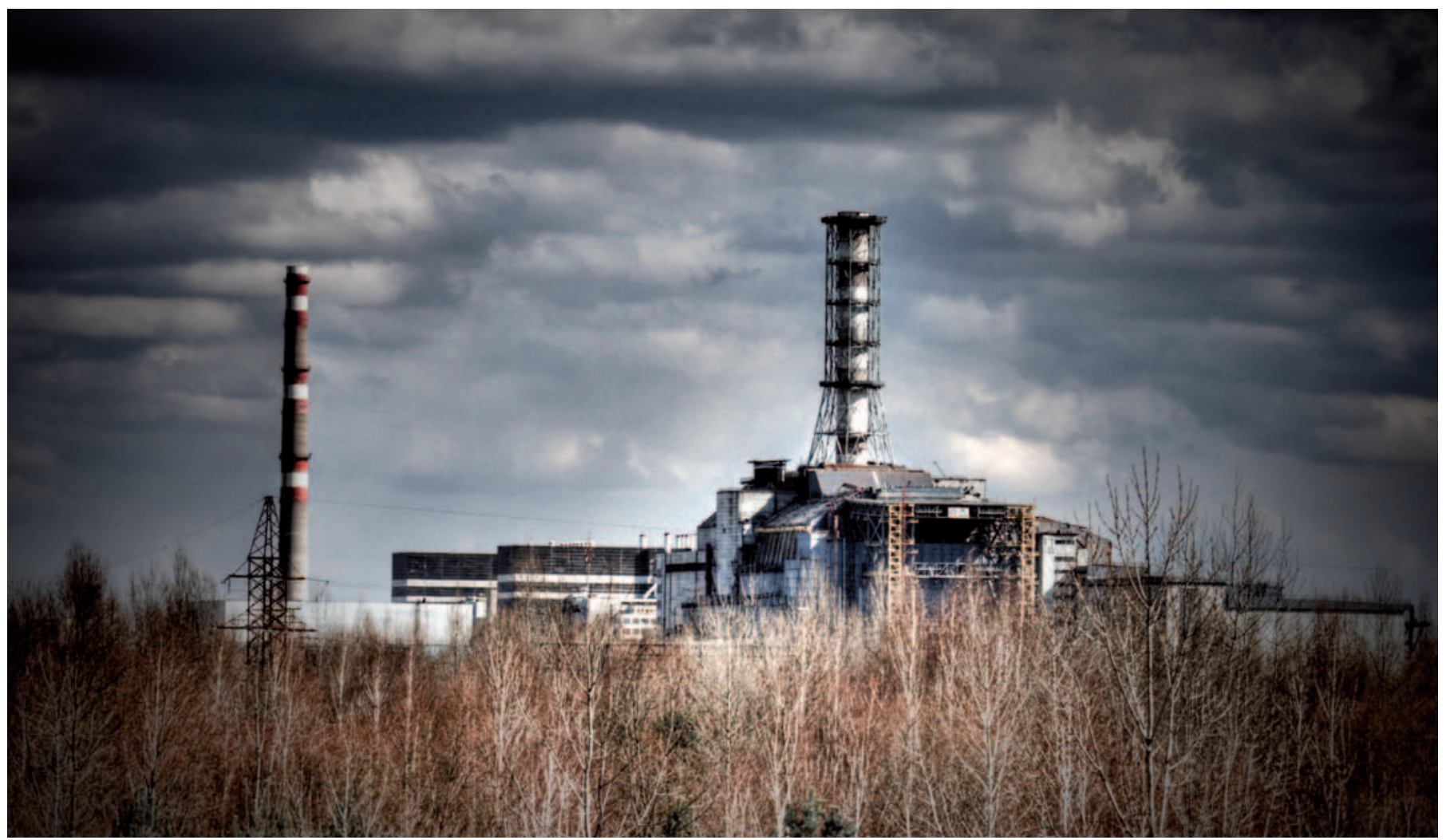

Ghost from the past: encased in crumbling concrete, the deadly contents of Chernobyl's reactor number 4 still exert a far-reaching effect on the area.

\title{
Chernobyl's legacy
}

\section{Twenty-five years after the nuclear disaster, the clean-up grinds on and health studies are faltering. Are there lessons for Japan?}

\section{BY MARK PEPLOW}

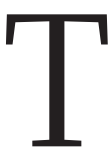

he morning train from Slavutych is packed with commuters playing cards, browsing e-readers, or watching the monotonous flood plains pass by. It looks like any other routine journey to work. But rather than facing a crush through subway turnstiles at the end of the 40-minute trip, the workers are met by a row of full-body radiation monitors. It is the start of another day at the Chernobyl power plant, the site of the world's worst civilian nuclear disaster.

As the train trundles through the bleak Ukrainian countryside, another nuclear crisis is unfolding halfway around the world. Barely a week after the partial meltdown at the Fukushima Daiichi nuclear power station, it is no surprise that some of the chatter on the train turns to the incident there. "It looks bad," says one commuter. "But not as bad as Chernobyl," he adds, with a hint of grim pride.

When Chernobyl's reactor number 4 exploded in the early hours of 26 April 1986, the ensuing blaze spewed 6.7 tonnes of material from the core high into the atmosphere, spreading radioactive isotopes over more than 200,000 square kilometres of Europe (see 'The hottest zone'). Dozens of emergency workers died within months from radiation exposure and thousands of children in the region later developed thyroid cancer. The region around the plant became so contaminated that officials cordoned off a 30-kilometre exclusion zone that straddled Ukraine's border with Belarus. Today, a staff of about 3,500 enters the zone each day to monitor, clean and guard the site, where remediation work will continue for at least another 50 years (see 'Half-life of a disaster').

So far, the Fukushima accident is less severe. Radiation levels measured near the Japanese power plant have been less than those at Chernobyl after the blast there (see 'Exposure in context'). And although radiation has spread from Fukushima, it does not match the amounts that rained down in the region around Chernobyl.
Despite those differences, the quarter-century of work following the Chernobyl disaster will offer some important lessons for Japan as the nation begins to assess the health and environmental consequences of Fukushima. The problems that followed Chernobyl also provide a grim reminder about the value of accurate information. Officials need to tell people immediately how to avoid the initial, most dangerous, exposure; yet in the longer term, scientists and the government must battle against unnecessary concern over low-level doses of radiation, which often causes more harm than the radiation itself.

In some ways, the connection between the two accidents may yield the biggest benefits for Chernobyl. For a brief window of time, the world has again focused attention on the largely overlooked work there. The renewed interest may spur nations to chip in the cash needed to complete the clean-up of the site, and to carry out health studies that have languished for want of proper coordination and funding. "In recent years, Chernobyl has been neglected by funding agencies and, to an extent, the scientific community," says Jim Smith, a radioecologist at the University of Portsmouth, UK, who has studied the consequences of the accident for 20 years. "But there is still more to learn from Chernobyl about decommissioning and the effects of the radiation," says Smith, who is touring the site with a group of other scientists.

After clearing a security checkpoint, the visiting researchers board a bus that heads 
towards the heart of the ageing power plant. They pass abandoned buildings and bump along potholed roads running beneath archways made of piping; since the accident, pipes have been laid above ground to avoid disturbing contaminated soil.

The visitors stop to look at the most visible reminder of the accident, the concrete sarcophagus that entombs the shattered reactor building. Completed hastily in November 1986, the sarcophagus was built to contain the escaping radiation, but it is now crumbling and streaked with rust. Smith whips a dosimeter out of his rucksack and poses for a photograph in front of the sarcophagus. The reading is $5 \mu \mathrm{Svh}^{-1}$ : about 10 minutes of exposure at that level equals the same dose as an arm X-ray.

The plant's bright main office is a stark contrast to the sarcophagus. Stained-glass windows depict - in glorious socialist-realist style - the harnessing of atomic energy. But the plant has not produced power since 2000, when the last reactor was shut down. Valeriy Seyda, a deputy director of the Chernobyl Nuclear Power Plant, explains that the plant's top priority now is to construct a new confinement shelter for reactor 4 before the sarcophagus becomes too unstable. If it collapses before the new shell is in place, it could throw up a cloud of radioactive particles and expose the deadly remnants of the reactor.

\section{REPLACING THE RUSTING TOMB}

The plan is to build an enormous steel arch adjacent to the reactor and slide it along a runway to cover the building. The arch will reach 105 metres high, with a span of 257 metres the world's largest mobile structure, according to its designers. It is expected to be in place by 2015 and should last for 100 years. It will enable robotic cranes inside to dismantle the sarcophagus and parts of the reactor. Longterm plans call for finishing the clean-up work at Chernobyl by 2065.

Some of the concrete trenches for the project are in place. But the international Chernobyl Shelter Fund that supports the US\$1.4-billion effort still lacks about half of ऐ that cash, and the completion date has slipped 㟧 by almost ten years since the shelter plan was agreed in principle in 2001. One of the key goals of a forthcoming conference - Chernobyl, 25 Years On: Safety for the Future - to be held in Kiev on 20-22 April is to secure more cash commitments from international donors. Meanwhile, Chernobyl is developing long-term storage facilities for the debris that $\Sigma$ will be hacked out of reactor 4 ; and for more than 20,000 spent fuel canisters from the site's other reactors, a facility that will cost about $€ 300$ million (US\$420 million).

$\rightarrow$ NATURE.COM

For a slideshow and other extras see: go.nature.com/bmliu6 waste - partly because of persistent flooding in some of the waste-storage buildings and reactor 4's turbine hall. Every month, at least 300,000 litres of radioactive water must be pumped out of the structures and stored on site.

The main cause of this flooding is Chernobyl's brimming cooling pond, which artificially elevates groundwater levels in the area. Alexander Antropov, a Chernobyl veteran with ice-blue eyes and a cool manner to match, is in charge of a project to decommission the pond. The term 'cooling pond' usually refers to the containers where spent fuel rods are stored until their radiation dissipates enough that they can be put into long-term storage. But Chernobyl's pond is actually a vast reservoir covering 22 square kilometres into which water from the reactor cooling systems was discharged. The pond also contains long-lasting radioactive material such as caesium-137 and strontium-90, which rained down after the explosion. Besides causing flooding at the plant, the high water levels in the cooling pond raise the risk that a weak dyke along its east side will burst, which would send water coursing into the Pripyat River. Radioactivity in the escaping water would be quickly diluted by the river, so although it would not significantly raise exposure levels for people downstream, it could cause panic among the local population.

Antropov says that his team cannot simply lower the water levels in the pond because they don't know what effect microscopic radioactive sediment particles would have if exposed. In the meantime, the team maintains the status quo by pumping water from the Pripyat River into the pond at a cost of a few hundred thousand euros per year. But the long-term plan is to lower the water level by 7 metres to form a patchwork of 10-20 smaller ponds that would keep the most dangerous sediments in place. The project would cost $€ 3$ million to $€ 4$ million, says Antropov. He is already in discussions with the relevant regulators and is optimistic that the necessary feasibility studies and environmental impact assessments can be completed.

But the effort has been a long time coming. The decommissioning plan is more than a decade old, and was supported by a 2005 survey for the European Commission, led by Smith. Once again, money has been a key factor in the delay. The major parts of Chernobyl's decommissioning plan are paid for by international funds, but the cooling pond project is not. Nor is the research needed to satisfy the regulators. "Most of our own activities come from the Ukrainian budget, and we are not a rich country," says Seyda.

After leaving the cooling pond, the visitors stop at Pripyat, an abandoned town just 3 kilometres from the reactor complex. Some 44,000 residents were evacuated the day after the accident, and many of their belongings still litter the decaying buildings. Antropov once lived here - his daughter was a few months old at the time of the accident - and as deputy
100 Owing to a flawed safety test, 100 Chernobyl's reactor 4 explodes, 26 APRIL scattering debris from the core 26 APRIL over a wide area.

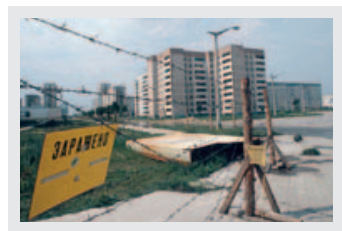

27 APRIL A day after the blast, some 44,000 residents are evacuated from Pripyat, just $3 \mathrm{~km}$ from the reactor.

5 MAY The fire in the reactor is finally extinguished, having released 6.7 tonnes of radioactive material over 200,000 square kilometres.

6 MAY People and cattle are evacuated from a 30-kilometre exclusion zone around the plant.

AUGUST 4 months after the blast, 28 emergency
workers have died from acute radiation
sickness, caused by massive doses of radiation.

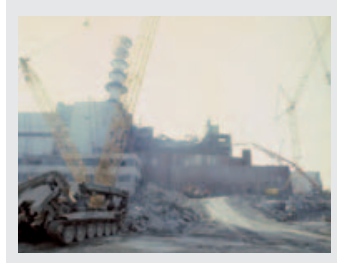

NOVEMBER

Workers complete a concrete sarcophagus around the shattered reactor to limit further release of radiation.

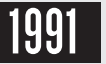

Cases of thyroid cancer in local children have risen ten-fold from previous levels.

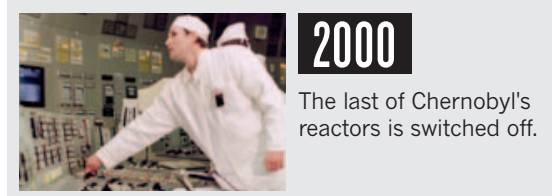

2005 The United Nations Chernobyl Forum reports that no more than 4,000 people will die from the reactor's fallout.

2011

25th anniversary conference expects to see lobbying for more funds for clean-up and health studies.

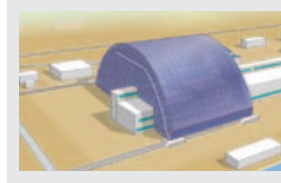

\section{5}

New safe confinement shelter projected to be completed.

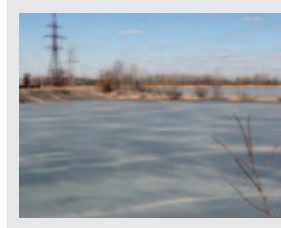

\section{0}

Remediation efforts at plant's cooling pond scheduled to be completed. 


\section{THEHOTTEST ZONE}

Shifting wind patterns carried radiation from the Chernobyl blast across much of Europe (right). Plant operators are now trying to lower water levels in a massive cooling pond (below) filled with radioactive water and sediments.
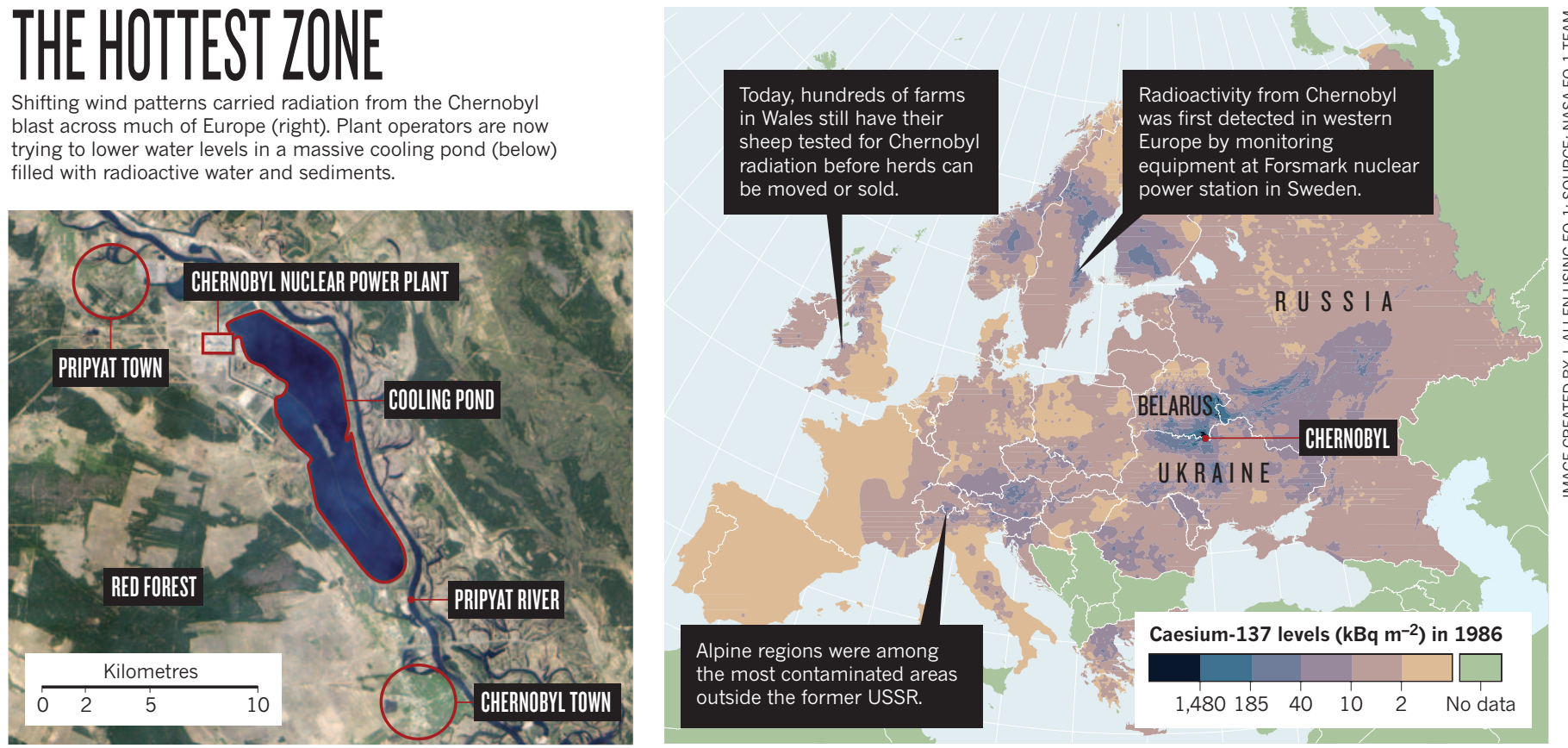

chief of the town's Communist party office, he was responsible for evacuating part of the town. Because he worked as a senior engineer at the nuclear plant, he knew that the disaster would have repercussions for decades to come. "I understood that I would never return to live in Pripyat," he says, in an uncharacteristically soft voice. "I still feel some sense of loss."

The evacuees from Pripyat also live with lingering fear about the radiation they were exposed to before fleeing their homes. Along with millions of others from the surrounding regions, they often attribute any sign of ill health to the accident. But pinning down Chernobyl's true public-health impact has proved remarkably difficult.

There is little disagreement about the terrible fate of the workers who brought Chernobyl's stricken reactor under control. Of 134 emergency workers diagnosed with acute radiation sickness, 28 died from their exposure within four months. Another 19 have died since from various causes, and many of the surviving workers now have cataracts and skin injuries.

More than 5,000 cases of thyroid cancer have so far been seen in people who were children at the time of the accident and lived in contaminated areas of the former Soviet Union - a more than ten-fold increase from normal levels (adults were mostly unaffected by the disease). Most of these cases were caused by drinking milk contaminated with radioiodine. Fewer than 20 of these people have died, but the sheer number of cancers, and their rapid onset within 5 years of the accident, surprised many epidemiologists.

This triggered a plethora of thyroid studies, most notably a long-term cohort study of 25,000 people in Ukraine and Belarus who were children in 1986 that is being coordinated by the US National Institutes of Health's
National Cancer Institute (NCI) in Bethesda, Maryland. The latest results from the Ukrainian section of this cohort ${ }^{1}$ confirm previous findings that the incidence of thyroid cancer is proportional to the size of the dose, with a particularly high risk seen in younger people and in those who were iodine-deficient due to poor diet. The research is having a direct impact in Japan, where those at risk of exposure are being given potassium iodide tablets to prevent the uptake of radioiodine in their thyroid.

The NCI oversees a second cohort made up of liquidators, a group of more than half a million people sent into the exclusion zone to help clean up and monitor the area after the initial emergency phase of the accident. Liquidators have a slightly raised risk of developing cataracts, and possibly a small increased risk of leukaemia ${ }^{2}$

\section{LONG-TERM EFFECTS}

But what was the impact on the wider population? Various studies have tried to estimate how many deaths Chernobyl will eventually cause across the whole of Europe, but their answers range from a few thousand to hundreds of thousands ${ }^{3}$. Cancer causes about a quarter of all deaths in Europe, so teasing out Chernobyl's far-reaching influence would probably be impossible, say epidemiologists. Moreover, focusing on such intangible numbers can distract from the much broader social impact of the accident. In Ukraine and Belarus, hit hard by the break-up of the Soviet Union in 1991, lingering fears about radiation are thought to have contributed to a sense of hopelessness that is linked to high rates of alcoholism and smoking - factors that have a much bigger health impact.

"There's tremendous uncertainty for these people," says Elisabeth Cardis, a radiation epidemiologist at the Centre for Research in Environmental Epidemiology in Barcelona, Spain. "Some think they are doomed because of their radiation exposure." Further research could provide convincing evidence that Chernobyl's radiation did not significantly harm the wider population, but "we won't know unless we look", says Dillwyn Williams, a cancer researcher at the Strangeways Research Laboratory in Cambridge, UK.

A handful of Chernobyl studies have found small increases in rates of breast cancer and cardiovascular disease, but they did not properly account for confounding factors, such as nutrition, alcohol consumption and smoking habits. And although some researchers have claimed to see an increase in genetic mutations in the children of parents irradiated after Chernobyl $l^{4}$, there has been no similar evidence of hereditary effects even in the children of Japanese atomic bomb survivors, who on average received much larger radiation doses.

This means that there is still a substantial gap in the overall understanding of Chernobyl's health effects, says Williams. The problem is exacerbated by the piecemeal nature of previous studies. "There has been a failure of European-level coordination on this," he says.

Williams hopes that there is now a chance to establish a Chernobyl Health Effects Research Foundation, which would mirror the highly effective Radiation Effects Research Foundation that monitors the long-term health impacts of the atomic bombs in Japan. Together, the efforts could reveal the differences between the single short-term dose of external radiation delivered by the atomic bombs, and the lowlevel long-term exposure seen after Chernobyl. Long-term doses were once thought to carry much less risk than the immediate exposure, but evidence is accumulating that the risks 
may be much the same ${ }^{5}$. If confirmed, it would mean that people routinely exposed to lowlevel radiation have a greater chance of health problems than previously thought.

The European Commission has funded Williams, Cardis and a core group of other scientists to develop a research plan, dubbed the Agenda for Research on Chernobyl Health $(\mathrm{ARCH})$, that maps out how the existing cohorts could be used to study a wider range of diseases, such as breast cancer and cardiovascular disease, and to address the questions about the long-term effects of low doses. The liquidator cohort, for example, is six times larger than that of atomic bomb survivors, with a much wider range of exposure doses. It could show how risk varies over that large range of doses and uncover rarer effects at lower doses. It could also help to reassess the threshold dose to prevent nuclear workers from developing problems such as cataracts.

ARCH also suggests testing the feasibility of setting up new cohorts including liquidators' offspring and highly exposed evacuees, along with a tissue bank. The bank may reveal whether people's genetic make-up influences their susceptibility to radiation - key information for determining how individuals are likely to respond to the radiation received during medical procedures such as X-ray scans and radiation treatment.

There are several hurdles, however, to getting ARCH off the ground. The project needs support from the NCI, which stopped funding active clinical monitoring of the thyroid cohort in 2008 because of budgetary constraints. And ARCH's proposals would also require better access to medical records in Ukraine and more information about participants' lifestyle factors - both potentially tall orders.

The ARCH plan will be presented at the 25th anniversary conference in April, and Cardis hopes that a positive reception will prompt the European Commission to boost its support. It is likely to be difficult to secure a long-term commitment for the studies, which will cost about $€ 3$ million to set up, but that cost is minor compared with the billions that will be spent on remediation at Chernobyl, says Williams.

Beyond obtaining the necessary funds, researchers will also require cooperation from participants to expand the cohort studies. That could be difficult. Gennady Laptev, now a hydrologist based at the Ukrainian Hydrometeorological Institute in Kiev, was a liquidator for three years, and says that he stopped attending his medical check-ups about ten years ago because they were too time-consuming. "They never found any major health problems," he says.

Laptev's work involved flying by helicopter from Kiev to Chernobyl twice a week to take radiation readings and collect soil and water samples for analysis. "Nobody forced me to do the work - I did it because it was interesting, and I really enjoyed it," he says. But after three years, he became worried about the risk of working near the plant, so he took a job researching how radioisotopes dispersed in the local water system.

Concerns about radiation exposure continue to plague residents in the region, and the planned studies could provide the answers they so desperately need about Chernobyl's

\section{"Some think they are doomed because of their radiation exposure."}

\begin{tabular}{|c|c|}
\hline \multicolumn{2}{|c|}{$\begin{array}{l}\text { EXPOSURE IW GONTEXT } \\
\text { Many emergency workers at Chernobyl received lethal doses of radiation, but the broader public, even } \\
\text { those living in the contaminated zone, were exposed to levels on a par with some medical procedures. }\end{array}$} \\
\hline Dose (mSv) & Source/implication \\
\hline Up to 5,000 & One minute's exposure to Chernobyl core shortly after explosion \\
\hline 1,000 & $\begin{array}{l}\text { Causes temporary radiation sickness, including nausea and decreased white-blood- } \\
\text { cell count }\end{array}$ \\
\hline 250 & Upper annual limit allowed for Fukushima emergency workers \\
\hline 120 & Average total dose received by liquidators at Chernobyl (1986-90) \\
\hline 30 & $\begin{array}{l}\text { Average total dose of external radiation received by evacuees from Chernobyl plant } \\
\text { and surrounding area }\end{array}$ \\
\hline 20 & Average annual limit for nuclear-industry workers \\
\hline 9 & $\begin{array}{l}\text { Total dose received by the } 6 \text { million residents in contaminated areas }\left(>37 \mathrm{kBq} \mathrm{m}^{-2}\right) \text { in } \\
\text { former USSR }\end{array}$ \\
\hline 9 & One computed-tomography (CT) scan \\
\hline 9 & Annual exposure of airline crew flying regularly between New York and Tokyo \\
\hline 3 & One mammogram \\
\hline 2.4 & Average annual background radiation globally \\
\hline 0.3 & Total dose received by each resident of Europe for 20 years after Chernobyl \\
\hline
\end{tabular}

real health legacy. "I have a house in a village near Slavutych, on contaminated territory," says Antropov during the site visit. "Two of my neighbours died of cancer, and this was probably the result of their radiation doses."

\section{LESSONS FOR JAPAN}

It's too early to say how the Chernobyl health studies will help those affected by the Fukushima accident. But Chernobyl has already given the world a lasting lesson on the importance of clear communication during a nuclear disaster, and in the years afterwards.

There was no systematic distribution of prophylactic potassium iodide to the people around Chernobyl, and Pripyat's children were allowed to play outside during the day after the accident, while the reactor continued to burn. "The failure to rapidly communicate radiation risks at Chernobyl led to people receiving higher radiation exposures than was necessary," says Smith.

The Japanese government has been lambasted for not keeping citizens well informed about the accident there. But it was swifter to act than Soviet officials were, ordering the evacuation of people who live near the plant within hours of recognizing the growing nuclear emergency, and expanding that evacuation zone to a radius of 20 kilometres the following day. As well as distributing potassium iodide, the Japanese government banned the sale of food and milk produced in the provinces around the stricken plant. "The Japanese have done exactly the right thing," says Andrew Sherry, director of the Dalton Nuclear Institute at the University of Manchester, UK.

Ultimately, says Smith, Chernobyl's most important lesson for Fukushima is that a nuclear accident haunts a region long after the reactors have cooled. If areas of Japan are significantly contaminated with radioactive caesium-137, which loses half its radioactivity in 30 years, the government may have to maintain an exclusion zone for decades. Decommissioning the Fukushima reactors may also take decades, depending on the extent of damage to their cores. And the uncertainty surrounding the health risks may exact a psychological toll that could surpass the physical harm from the radiation, adds Smith.

Many of the workers at Chernobyl understand those lessons all too well as they shuffle onto the train to Slavutych at the end of their day. The workers will return to tend to the plant tomorrow and the next day - and for many years to come. $\square$ SEE EDITORIALP.547

Mark Peplow is Nature's news editor.

1. Brenner, A. V. et al. Environ. Health Perspect doi:10.1289/ehp.1002674 (2011).

2. Cardis, E. \& Hatch, M. Clin. Oncol. doi:10.1016/ j.clon.2011.01.510 (2011)

3. Peplow, M. Nature 440, 982-983 (2006)

4. Dubrova, Y. E. et al. Nature 380, 683-686 (1996).

5. Health Risks from Exposure to Low Levels of lonizing Radiation: BEIR VII Phase 2 (NRC, 2006); available at http://go.nature.com/r7jeca. 